\title{
"NO ME MUEVE, MI DIOS..."
}

En su reciente artículo sobre "El anónimo del soneto No me mueve, mi Dios ..." (NRFH, IV, 1950, págs. 254-269), Marcel Bataillon investiga las fuentes del famoso soneto, que aparece impreso por primera vez en 1628 , en la Vida del espiritu de Antonio de Rojas ${ }^{1}$ y que en 1634 ó $163_{3}$ agregó fray Miguel de Guevara al manuscrito de su Arte doctrinal . . para aprender la lengua matlaltzinga; Bataillon llega a la conclusión de que el soneto, relacionado como está con la doctrina del Beato Juan de Ávila en su Audi filia, y con la de la escuela italiana de los spirituali y la del Puro amor de Dios que floreció en la Francia de Luis XIII, es "anónimo" en el sentido de que su autor, quienquiera que haya sido (y entre los eclesiásticos españoles existía la tradición de no firmar poemas religiosos), no tenía otra ambición literaria que la de dar una poderosa expresión a las creencias de su espiritualidad "cristocéntrica". Por eso Bataillon se ve obligado a rechazar la atribución a Lope de Vega, propuesta por Montoliu, pues "el estilo es otro. No hay en todas las Rimas sacras un solo soneto tan desprovisto como No me mueve ... de esos hallazgos expresivos que derrocha la pluma de Lope, no hay otro tan fundado en mero vigor afirmativo e insistente".

Por mi parte, estoy convencido de que, tanto en su explicación del "porqué del anonimato" del soneto como en su distinción entre los "hallazgos expresivos" de Lope y el "vigor afirmativo e insistente" de nuestro soneto, el procedimiento de Bataillon es irreprochable. El ilustre hispanista no opone expresamente la opinión de Sister Mary Cyria Huff", según la cual el poema se nos muestra "en una forma tan sencilla e inteligible", que "se comprende la popularidad de que goza en todas las clases sociales", opinión que se remonta a $\mathrm{Pfandl}^{3}$, el cual ve en $N o$ me mueve, mi Dios... un "seelenvolles Gedicht", una muestra de "Stimmungspoesie" que con toda razón conmueve el alma de los españoles. En mi opinión, estamos aquí en presencia de la antinomia que se manifiesta en toda poesía "popular". Fl hecho de que un poema se haya hecho popular no quiere decir

'En la pág. 25. del citado artículo se lee "1626" por errata de imprenta; para su estudio, Bataillon utiliza una reimpresión de 1630.

"The sonnet "No me mueve, mi Dios...", Washington, 1948, pág. 52.

${ }^{3}$ Geschichte der spanischen Nationalliteratur in ihrer Blïtezeit, pág. 148. 
que sea tan sencillo como lo hubiera concebido un poeta que escribiera para el pueblo. Sabido es que la poesía popular española (y árabe) suele ser de índole bastante refinada. Por cierto que el propio Pfandl debió de sentir esta antinomia, a juzgar por sus palabras: "No es un obstáculo a priori para ello [para la difusión del soneto en la tradición oral] la forma artística culta, porque seguramente el pueblo veía en él, no ya un soneto, sino sencillamente una poesía o cancioncilla piadosa". Sólo que parece pensar que si el pueblo podía ver en él "una poesía o cancioncilla piadosa", el soneto era esencialmente eso. Por lo tanto, trataré de mostrar, mediante un ceñido análisis del soneto, su carácter artístico y aun refinado. (En el texto que aquí doy sigo la versión más antigua).

No me mueue, Señor, para quererte el cielo que me tienes prometido, ni me mueue el infierno tan temido para dejar por eso de quererte [var. temerte, ofenderte].

Mueues me tú [var. Tú me mueves], mi Dios, mueue [me] el verte clauado en vna cruz y escarnecido, mueue me el ver tu cuerpo tan herido, mueuen me tus affrentas y tu muerte.

Mueue me, en fin, tu amor en tal [var. y en tal] manera, que si no vbiera cielo yo te amara, y si no vbiera infierno te temiera.

No tienes que me dar porque te quiera, porque [var. que] si quanto espero no esperara, lo mismo que te quiero te quisiera.

En cuanto al contenido, he aquí lo que dice el mismo Pfandl:

Su carácter notoriamente místico consiste en que exalta el despertar del amor a Cristo crucificado como fruto de la meditación. I legar por medio de la meditación a la contemplación y al amor y unión amorosa, o, dicho en otra forma, un conmovedor realismo en la representación, y por este medio un ahondamiento de la meditación hasta encender la llama del amor: tal es el contenido y la concatenación de sus espléndidos versos.

Acerca de la forma, lo único que añade es que los cuartetos "se cuentan entre lo más hermoso que se ha compuesto en español; pero el último terceto adolece del defecto de repetir la palabra porque, con distinto sentido cada vez". Es claro, pues, que Pfandl no apreciaba plenamente más que los cuartetos (y quizá el primer verso del primer terceto), en los cuales se observa sin duda un tránsito de la "medita- 
ción" (sobre las razones de amar a Cristo) a la "contemplación" (de Cristo crucificado) y de aquí al "amor" de Cristo, mientras que los cinco últimos versos le parecían frustrados, quizá no sólo por la repetición de la ambigua palabra porque, sino por su carácter intelectual -digámoslo así provisionalmente-, que no respondía muy bien a su idea de "cancioncilla piadosa" recitada por la gente del pueblo. En otras palabras, Pfandl no comprendió el poema entero, esto es, la unidad del poema, que es de estructura ciclica, intelectual en su comienzo y en su final, emocional en el centro (segundo cuarteto más el verso 9). Esa crisis emotiva causada por la contemplación del Crucificado es lo que permite al poeta volver a formular su convicción sobre una base intelectual nueva y reforzada.

Fl poema descansa sobre una firme estructura intelectual que, con términos tomados del soneto mismo, puede expresarse como sigue: infierno.

I. No me mueve, mi Dios, para quererte, ni el cielo ni el

II. Tú me mueves, Señor ..., tu amor [verso 9].

III. Aunque no hubiera cielo ni infierno, lo mismo que te quiero te quisiera.

Esta estructura tripartita (con el amor del verso 9 en posición en cierto modo independiente) no se encuentra en los textos en prosa de Juan de Ávila: en uno de ellos (BAtair.lon, pág. ${ }_{5} 5^{6}$ ), que corresponde a la parte III de nuestro soneto, se habla de los justos que hacen el bien "aunque no hubiese infierno que amenazase, ni paraíso que convidase, ni mandamiento que constriñese" (triple período concesivo); en el otro, correspondiente a la parte II, la contemplación de todos los rasgos del espectáculo de Cristo crucificado invita al amor: "lodo cuanto vieren mis ojos, todo convida a amor: el madero, la figura y el misterio, las heridas de tu cuerpo; y sobre todo, el amor interior me da voces que te ame..." Un detalle original del autor de nuestro soneto es la fusión de la idea del perfecto y desinteresado amor a Cristo con la del poder redentor de la Pasión en la forma triádica 'ni cl cielo ni el infierno' - 'cl amor de Cristo manifestado en la cruz' - 'aunque no hubiera cielo ni infierno'.

En cuanto al himno javeriano o jesuítico de 1631, O Deus! ego amo te, cuya relación con nuestro soneto no está clara todavía (B $\mathbf{B}_{\mathrm{A}-}$ TAILI.on, pág. 265 ), presenta ciertamente un esquema tripartito, en el cual la consideración 'cielo-infierno' constituye el marco de la contemplación de Cristo crucificado, pero con un retorno casi textual, en el final, de los versos non ul in caelo salves me / aul in aelernum dammes me. Para el autor de este himno, lo principal es la relación del cur igitur non amem le? con el Jesu amanlissime, el carícter mutuo del amor entre Dios y el hombre: de ahí su insistencia en que Cristo murió propter me ac pro me, que totum me amplexus [est] 
in cruce, que sicut tu amasti me, sic amo et amabo le; el concepto amare se repite ocho veces, como si el místico hubiera querido cantarnos un arrullo del amor que todo lo abarca. El carácter cíclico del himno se lunda en el ciclo del amor que incluye al Redentor y al redimido, y no en el ciclo psicológico que va de la meditación intelectual a la visión, y de nuevo a la meditación intelectual: en efecto, las concesivas del soneto No me mueve ... faltan en el himno.

$\mathrm{Si}$ éste fuera realmente la fuente del soneto español, y no al contrario, el anónimo poeta de No me mueve ... sería de todos modos quien escribió una versión poética del Puro amor al Crucificado liberándola de su carácter de canción de iglesia o de "cancioncilla piadosa" y dándole -aquí me atrevo a exponer mi teoría- el sobrio y riguroso carácter de un ejercicio espiritual en el sentido de San Ignacio de Loyola. Citaré la descripción que hace Pfandl (op. cit., pág. 41) del cuádruple desarrollo psicológico a que ha de someterse el espíritu de los discípulos de San Ignacio:

I as potencias del alma son despertadas y llamadas a la actividad en forma metódica y gradualmente intensificada. La memoria recibe y desarrolla el material que se le da. La imaginación lo cerca y lo penetra, le da vida y fuego, le atribuye movimiento, forma, luz, fuerza y plasticidad, de manera no desordenada, por supuesto, sino gobernada y guiada siempre por la fuerza del entendimiento. Viene entonces la emoción, la cual, en forma negativa o positiva, por el camino de la conmoción o el de la elevación, concentra en el individuo la experiencia espiritual que hasta entonces ha sido impersonal, y parece hacerle ver su lugar y su parte, su debe y su haber en este mundo. Por último, el acto de la voluntad pone cima a este artificioso juego de las potencias del alma, con la resolución de aplicar la enseñanza positiva de ese aprendizaje a la disciplina, al dominio de sí mismo.

En cuanto a la segunda fuerza psíquica, la "imaginación" (Vorstellungskrafl), Pfandl nos advierte especialmente que no debemos confundirla con la "fantasía desbordante" (zügellos schweifende Phantasie), sino que hay que considerarla como la "facultad de representarnos ante los ojos del espíritu, con plástica nitidez, determinadas ideas. Esta imaginación, que - cosa significativa- San Ignacio y más tarde los místicos solían llamar entendimiento, es elemento esencial del realismo español".

A nadie se ocultará el paralelismo que hay entre nuestro soneto y el cuádruple ejercicio espiritual de San Ignacio. La parte I (no me mueve) es la doctrina tradicional, asimilada por la memoria, acerca del premio que en la otia vida recibe el amor y el temor de Dios (de esta doctrina tendremos que prescindir aquí); la parte II ( $t u$ me mueves) está consagrada a la imaginación, a la representación senso- 
rial de los sufrimientos de Cristo por el alma piadosa del creyente; el verso 9 (muéveme tu amor en tal manera) está destinado a producir la emoción en su connotación positiva: el amor de Cristo como fruto de la imaginación; la parte III contiene el "acto cumbre de la voluntad"' que decide, con firmeza y vigor, persistir en el amor a Cristo hasta en un caso extremo e inimaginable: aun cuando no hubiera cielo ni infierno. Nuestro poeta, probablemente un jesuíta -y Bataillon ha mostrado cómo los jesuítas se habían apropiado la idea del "puro amor"-, realizó genialmente la hazaña de combinar el tema del Puro amor en el sentido aviliano con la técnica psicológica ignaciana; más aún, de fundar sobre ésta una técnica poética de que San Ignacio nunca llegó a dar mustras (véanse las palabras de Pfandl acerca del prosaísmo del santo), aunque permaneciendo siempre muy cerca del rigor sistemático de aquel "general" - estratega, mejor dicho- de la psicología religiosa. El soneto, con su estructura dualtriádica, ofrecía una forma a propósito para el ejercicio espiritual, para la condensación poética, en una especie de "momento religioso" (lo digo pensando en el "momento musical" de Schubert), del paso del pensamiento religioso al sentimiento y a la resolución. Las diversas partes de que se compone naturalmente un soneto podían desarrollarse a partir de las etapas que recorre el proceso psicológico, podían adaptarse a ellas, y la estructura bipartita de la primera parte podía repetirse en la última en un nivel superior: al final queda trascendida la dicotomía 'amor-temor'. El arte del poeta consiste en haber presentado las cuatro etapas sucesivas de adhesión a Dios compendiadas en un apóstrofe directo a Dios que tiene el timbre del lenguaje hablado, de una oración pronunciada en el momento mismo, sin huella alguna del cuádruple esquema de San Ignacio (lo cual explica que haya escapado, hasta ahora, a la atención de los críticos). El arte del poeta ha encubierto la armazón arquitectónica.

En la primera parte (primer cuarteto) no encontramos una visualización sensorial, sino sólo una afirmación dogmática, de carácter negativo, acerca de lo que no me mueve, y en forma de díptico. Fsta actitud de "no ver" el cielo y el infierno no es de ningún modo normal en la devoción cristiana: en la balada que Villon pone en boca de su madre, fermme povrette et ancïenne y sin letras, lo que la mueve a contrición es precisamente el cielo y el infierno según como aparecen representados en los muros de su parroquia:

$$
\begin{aligned}
& \text { au moustier voy dont suis paroissienne, } \\
& \text { paradis paint, ou sont harpes et luz, } \\
& \text { el ung enfer on dammez soml boulluz. }
\end{aligned}
$$

En la parte II (segundo cuarteto), excluídas ya las negativas, el Tú me mueves (si aceptamos esta variante) viene a ser la apasionada 
exclamación del alma creyente que anhela unirse en su imaginación con Cristo, con todo Él, con la persona concreta del Dios personal. Una expresión análoga encontramos en el himno javeriano: $T u, t u$, mi Jesu, totum me amplexus es in cruce; pero aquí recae el acento no tanto en la persona concreta de Dios cuanto en su extraordinario amor al hombre, su amoroso abrazo al hombre entero al morir en la cruz (totum se refiere a me, mientras que el tú del soneto presupone un totus referido a $T u$ ). Es evidente la diferencia que hay entre los "hallazgos expresivos" de Lope y también del himno latino, y el "vigor insistente" del soneto, la diferencia, diría yo (adoptando la distinción establecida alguna vez por Franz. Dornseiff), entre la expansión me tafórica y la expansión enfáti ca del lenguaje: la metáfora 'muerte de Cristo==abrazo que da Cristo al hombre' añade su vividez visual al hecho expresado, mientras que el enfático tú toma en serio, por así decir, la propia palabra tú ('tú en tu profundidad y en tu totalidad'), enriquece la frase, no extendiéndola, sino ahondándola. La misma expansión enfática aparece en el empleo del verbo mover: en los cuatro primeros versos sólo se emplea en sentido causal (no me mueve para quererte... 'no es [el pensamiento del cielo y del infierno] la causa de que yo te ame'), pero en el verso quinto nos encontramos con el empleo absoluto 'mover (emocionalmente)', el cual nos permite visualizar la totalidad del sentimiento, paralela a la totalidad del sujeto tú: 'tú en tu totalidad me conmueves a mí en mi totalidad'. Y ese enfático mueve, repetido cinco veces, es lo que prevalece en el segundo cuarteto y en el verso 9, como para insistir en la emoción producida por la imaginación. En la enumeración que sigue de los aspectos "conmovedores" del espectáculo de la crucifixión tampoco hay lugar para razonamientos metafísicos o para conceptismos religiosos (como en Juan de Ávila: "el costado abierto para recibirnos en tus entrañas, los pies enclavados para esperarnos"; este último elemento reaparece en el famoso soneto conceptista de Lope, "Pastor que con tus silbos amorosos..."), ni para una alusión a lo que Cristo hizo por el hombre (como en el himno latino: "haec propter me ac pro me peccatore"), ni siquiera para los aspectos cualitativos y cuantitativos de la Pasión inherentes al concepto agnus Dei (como en el himno: "Tulisti clavos, lanceam multamque ignominiam, innumeros dolores, sudores \& angores"). El discípulo de San Ignacio nos presenta sólo una visualización sensorial (muéveme el verte..., muéveme el ver...) y los elementos a los cuales se dirige esa visualización: clavado en una cruz (el artículo indefinido nos permite visualizar el hecho escueto, como si nos encontráramos con él por vez primera: 'Cristo en una cruz', no 'en la [bien conocida] cruz'); escar. necido; cuerpo tan herido (el adverbio tan, sentido íntimamente, está en lugar del multam y del innumeros del himno latino, y hace que la frase corresponda al infierno tan temido, como si este "cuerpo tan 
herido" ayudara a borrar el cuadro del "infierno tan temido"); tus afrentas (este único y sencillo plural reemplaza a los tres sustantivos del himno); y la culminación en el tiempo y en el vigor: tu muerte. En esta limitación del campo visual al acto de la visualización misma y a sus elementos escuetos percibimos aquel "dominio del entendimiento" de que habla Pfandl a propósito de la imaginación, esa sobria disciplina psicagógica inherente al ejercicio espiritual de la Compañía de Jesús. El verso Muéveme, en fin, tu amor, y en tal manera señala, con la frase adverbial en que termina, el final de la segunda etapa. A primera vista, el verso parece relacionarse únicamente con la precedente enumeración de los dolores de Cristo, contener su común denominador, o sea su amor (la sobriedad estilística que caracteriza a nuestro poeta no le permite siquiera especificar: 'su amor a la humanidad' o 'a mí mismo', como ocurre en el himno javeriano); pero la continuación y en tal manera (me mueve tu amor)..., que podría parecer una inútil coletilla, indica la acción del amor de Cristo sobre el amor del poeta; ' $y$ este amor es tan grande, que aunque ...' En el verso 9 se expresa la interacción mística entre Dios y el hombre, interacción que se muestra como apartada de nuestra mirada física, como detrás de un cortinaje, por así decir, y en ese sentido se manifiesta en él la tercera etapa de los ejercicios de San Ignacio: el despertar del afecto (en sentido "positivo") como resultado de la imaginación, de el ver. No se observa aquí una ruptura rítmica violenta como en la transición de la primera etapa a la segunda (Tú me mueves...), porque la acción mística consiste precisamente en la infusión imperceptible de la Gracia. El verso 9 es el centro cristológico del soneto -forma asimétrica por naturaleza-, cuya segunda parte puede acortarse porque las fuerzas laboriosamente preparadas en la primera parte actúan luego, digámoslo así, de manera automática: con la adhesión sentimental del creyente, Dios ha ganado su causa. El amor, que ahora debe entenderse como ' $\mathrm{mi}$ amor a Cristo', seguirá dominando en todo el terceto, y el muéveme, en fin, remate de la serie anafórica de seis miembros, sigue coloreando los tres versos de esta tercera estrofa.

Con los versos 10-11 volvemos a la dicotomía 'cielo-infierno' del comienzo: la plenitud de la emoción amorosa despertada en el poeta hace posible para él el no sentirse movido por las recompensas del más allá, el desentenderse de la existencia misma (aunque no hubiera ...) de esas recompensas. Estamos de nuevo en el plano intelectual, pero un plano intelectual caldeado, iluminado, fortalecido por la imagen que ha dejado la contemplación visual del Crucificado.

Aquí podría terminar el poema si su único propósito fuera mostrar el efecto de la imaginación: el Puro amor de Dios, prescindiendo de toda idea de recompensa; el ciclo se cierra en el verso 11. Pero, para plegarse a la práctica ignaciana, el poeta tenía que pintar todavía 
el acto que sirve de coronamiento, el de la voluntad: el verbo mover, puntal anafórico del poema, con su doble sugestión de 'emoción' y 'movimiento', tenía que ceder el terreno a la expresión de la resolución definitiva del creyente. Y esta convicción se expresa primero en una frase independiente de mover, una frase referida a Dios: No tienes que me dar por que te quiera (obsérvese el empleo absoluto o enfático de dar, paralelo al de mover). La abreviación característica de la segunda parte de todo soneto sirve aquí a un excelente motivo psicológico: a estas alturas, el poeta ya no puede pensar en el díptico 'cielo-infierno' o 'recompensa-castigo', sino en la característica "dadora" de Cristo y del Amor (no hacía falta un verso como "no tienes que castigarme para que te tema').

Los dos últimos versos no tienen más objeto que el de traer la respuesta positiva de la voluntad humana, no desde el punto de vista de Dios, sino desde el punto de vista del yo humano. Insisten en la inquebrantable resolución que tiene el alma de abrazar el Puro amor de Dios. Ahora puede prescindir no sólo de la existencia de cielo e infierno, sino de sus propias esperanzas (los temores ya han desaparecido en el verso 12, en el cual sólo se menciona el dar): aunque lo que espero no esperara. El Puro amor de Dios ha quedado ya entronizado en el centro emocional del alma: desde la dicotomía cósmica 'cieloinfierno' de la primera estrofa hemos ido penetrando cada vez más en el hombre, en ese centro intimo que únicamente espera (y no teme). El reditus in seipsum no podía ser más completo ${ }^{4}$.

Pfandl ha criticado el doble porque de los versos 12-13 (que en el primer caso significa 'para que' y en el segundo 'porque') y, en general, parece estimar los tercetos inferiores a los cuartetos. Ya hemos dicho que este juicio se explica porque Pfandl no vió en nuestro soneto el ciclo del exercitium spirituale que hace que el discípulo, tras la experiencia de la imaginación, vuelva a las verdades del punto de partida. En otras palabras, Pfandl y - a lo que puedo juzgar- los demás comentaristas no han logrado percibir un principio estilístico que gobierna los tercetos y que está destinado a darles el carácter de firme resolución, de inquebrantable fuerza en la fe, de eso que Bataillon llama con toda justicia "vigor afirmativo e insistente": el artificio consiste en el recurso acústico de la repetición de sonidos, que tiende a dar a esta parte del poema la calidad de una

${ }^{4}$ Entre los antecedentes de nuestro soneto citados por Bataillon, la más cabal expresión de la forma cíclica se encuentra, en efecto, en el pasaje del pseudo San Anselmo (siglos XII-XIII): "Nihil quaero nisi teipsum, quamvis nulla merces repromitteretur; licet inlernus et paradisus non essent, tamen propter dulcem bonitatem tuam, propter teipsum adhaerere vellem tibi". Pero aquí tenemos el procedimiento cíclico del predicador que vuelve a su afirmación inicial despućs de haberla demostrado; el procedimiento del psicagogo San Ignacio es diferente. 
"armadura de acero martillado". En los seis últimos versos aparece nueve veces la sílaba que, y cinco veces la sílaba te; a esto hay que añadir la figura de la adnominatio (espero - esperara, quiero - quisiera) y, por supuesto, las rimas logradas con formas verbales del mismo tiempo y modo (amara - temiera - esperara - quisiera $)^{5}$. Dentro del marco de estos recursos, el porque, con sus dos sentidos, no difiere del que repetido, que aparece en esta parte del poema con diversos significados: porque, aunque, etc. En todos estos casos, el elemento acústico del lenguaje (aliteración de $r, t, k$ ) supera al elemento semántico; la repetición de sonidos iguales produce una impresión de estabilidad y fijeza. La acumulación de tales recursos estilísticos, que recuerda más la técnica de los rhétoriqueurs y de Guittone d'Arezzo que la de los poetas renacentistas, suministra una "armadura del alma" comparable a la cota de malla medieval, ese flexible tejido hecho de aros metálicos entrelazados, armadura protectora sin intersticios por donde pueda penetrar un arma enemiga. Hay que observar también que el efecto de quiasmo se produce gracias a la posición del pronombre $t e$ (tanto más importante cuanto que se dirige a Dios), que en la primera mitad del soneto se emplea como enclítico después del verbo en infinitivo (quererte, ofenderte, verte) y en la segunda como proclítico después del verbo en modo personal (te amara, te temiera, te quiera, te quiero, te quisiera): es como si con los infinitivos se hiciera al creyente una propuesta que puede aceptar o rechazar, mientras que el verbo en modo personal expresa la voluntad del creyente: ya no se siente 'movido' a quererte, etc., sino que tiene que pronunciarse enérgicamente y sin ambigüedades: te quiero. Hemos dejado muy atrás la esfera del movimiento (mover) y del desarrollo, y hemos llegado al ser.

En vista de esta técnica semejante a la de los rhétoriqueurs, técnica bastante compleja y nada popular, que quizá no llegue a la sensibilidad moderna (como sin duda no llegó a la de Pfandl, crítico neo-romántico), pero que hubiera merecido la aprobación del Dante de las rime aspre e chiocce, me inclino a creer que el soneto No me mueve, mi Dios... pertenece - como vagamente lo intuyó Pfandlmás al final del siglo xvi que a las primeras décadas del xvII, y que surgió de un ambiente jesuítico que, como ha demostrado Bataillon, estaba impregnado (iya en $15^{80}$ y en Italia!) de las ideas de Juan de Ávila. El hecho de que, a pesar de la técnica poética revelada en la segunda parte, el poema se hiciera popular, puede deberse a que con-

5 Nuestro poeta no repite la raiz amare con la frecuencia con que lo hace el autor latino del himno javeriano. El hecho de que en español coexisten dos verbos con el mismo sentido, querer y amar, de los cuales sólo el segundo posee un sustantivo abstracto correspondiente (amor; la palabra querencia está excluída de la poesía de tono elevado), lo llevó a emplear ambas raíces dentro de su esquema de homologías (amara-quisiera). 
genia con el espíritu popular español, el cual, quizá a causa de la educación teológica recibida por todas las clases sociales durante siglos, se ha hecho más sensible que el de otras naciones tanto al elemento intelectual y dogmático como al elemento sentimental de la religión. Y, justamente porque el "ejercicio" ignaciano está destinado a abarcar toda la experiencia religiosa en sus diversas etapas, el soneto No me mueve, mi Dios...., que parafrasea todas esas etapas en sólo catorce versos, ha logrado llegar a esa totalidad o "exhaustividad" que caracteriza a los grandes poemas de la literatura universal.

The Johns Hopkins University. 